\title{
PERTUMBUHAN BIBIT KELAPA SAWIT (Elaeis quineensis Jacq) PADA MEDIUM ULTISOL YANG DIAPLIKASI KOMPOS Mucuna bracteata
}

\author{
Growth of Palm Oil Seedlings (Elaeis quineensis Jacq) on Ultisol Medium \\ Applied with Mucuna bracteata Compost
}

\author{
Taufik Ristumoyo Rambe, Adiwirman, Wawan \\ Program Studi Magister Ilmu Pertanian, Fakultas Pertanian, Universitas Riau \\ Jln.HR. Subrantas km 12,5 Simpang Baru, Telp/Fax (0761) 63270,63271 Pekanbaru 28293 \\ E-mail : taufikristumoyorambe@gmail.com \\ HP : 085363545544 \\ [Diterima: Oktober 2019; Disetujui: Desember 2019]
}

\begin{abstract}
The first problem faced in cultivating oil palm is the procurement of seeds. Ultisol soil when used for breeding media has several problems such as having a wet saturation of less than $35 \%$ at a depth of $125 \mathrm{~cm}$ below the upper limit of the argillic horizon. Ultisol has an acidity level of less than 5.5, low to moderate organic matter and low nutrition. The addition of organic material such as the LCC Mucuna bracteata compost is highly recommended because it will improve the physical, biological, and chemical properties of the soil, so that it increases the availability of nutrients in the soil to be optimal. This study aims to determine the effect of LCC mucuna bracteata compost on ultisol soil medium and determine the dosage/dose of LCC Mucuna Bracteata compost which provides the best growth of oil palm seedlings (Elaeis guineensis Jacq). This research was carried out experimentally with a Completely Randomized Design (CRD), consisting of 5 treatments and 4 replications. The results of this study indicate that distributing doses of $400 \mathrm{~g} / 8 \mathrm{~kg}$ of soil improved the physical and chemical properties of the soil and the vegetative growth of oil palm seeds.
\end{abstract}

Keywords: Ultisol, LCC Mucuna bracteata, Oil palm seeds, Mucuna bracteata compost

\begin{abstract}
ABSTRAK
Dalam usaha membudidayakan kelapa sawit, masalah pertama yang di hadapi adalah pengadaan bibit. Tanah ultisol bila digunakan untuk media pembibitan memiliki beberapa permasalahan seperti memiliki kejenuhan basah kurang dari $35 \%$ pada kedalaman $125 \mathrm{~cm}$ di bawah batas atas dari horizon argilik. Ultisol memiliki memiliki tingkat kemasaman kurang dari 5,5, bahan organik rendah sampai sedang,dan nutrisi rendah. Penambahan bahan organik seperti kompos LCC Mucuna bracteata sangat disarankan karena berfungsi memperbaiki sifat fisik, biologi dan kimia tanah, sehingga meningkatkan ketersediaan unsur hara di dalam tanah menjadi optimal. Penelitian ini betujuan untuk mengetahui pengaruh pemberian kompos LCC mucuna bracteata pada medium tanah ultisol dan menentukan dosis / takaran pupuk kompos LCC Mucuna Bracteata yang memberikan pertumbuhan bibit kelapa sawit (Elaeis guineensis Jacq) terbaik. Penelitian ini dilaksanakan secara eksperimen dengan Rancangan Acak Lengkap (RAL) yang terdiri atas 5 perlakuan dan 4 ulangan. Hasil penelitian menunjukkan bahwa pemberian dosis $400 \mathrm{~g} / 8 \mathrm{~kg}$ tanah mampu memperbaiki sifat fisik dan kimia tanah serta meningkatkan pertumbuhan vegetatif bibit kelapa sawit.
\end{abstract}

Kata kunci: Ultisol, LCC Mucuna bracteata, Bibit kelapa sawit, Kompos Mucuna bracteate.

\section{PENDAHULUAN}

Kelapa sawit (Elaeis guineensis Jacq.) merupakan salah satu primadona tanaman perkebunan yang memiliki prospek pengembangan cukup cerah. Minyak kelapa sawit menghasilkan produk yang kaya manfaat di berbagai industri, bahkan limbahnya masih dapat dimanfaatkan untuk industri kosmetik, oleokimia, hingga pakan ternak (Fauzi et al., 2012). Dalam usaha membudidayakan kelapa sawit, masalah pertama yang di hadapi adalah pengadaan bibit. Penggunaan bahan tanaman/bibit yang tidak jelas sumbernya akan menyebabkan timbulnya kerugian bagi pemilik kebun. Lubis (1992) yang menyatakan bahwa pembibitan 
kelapa sawit merupakan tahap awal dalam kegiatan budidaya kelapa sawit, dimana pembibitan yang telah dikelola dengan baik diharapkan akan menghasilkan bibit yang sehat dan berkualitas baik.

Pengembangan budidaya perkebunan kelapa sawit banyak di lakukan di lahan kering marjinal seperti tanah Ultisol. Tanah ultisol termasuk bagian terluas dari lahan kering yang ada di Indonesia yaitu 45.794.000 ha atau sekitar $25 \%$ dari total luas daratan Indonesia. Permasalahan budidaya tanaman kelapa sawit pada tanah Ultisol diperlukan pengembangan teknologi yang dilakukan dengan perbaikan mutu tanaman di pembibitan. Tanah ultisol bila digunakan untuk media pembibitan memiliki beberapa permasalahan seperti memiliki kejenuhan basah kurang dari 35\% pada kedalaman 125 $\mathrm{cm}$ di bawah batas atas dari horizon argilik atau kandik (tidak lebih dari $200 \mathrm{~cm}$ di bawah permukaan tanah mineral) atau $180 \mathrm{~cm}$ di bawah permukaan tanah mineral jika epipedon kelas - butir berpasir dan paling dangkal terdapat pada $125 \mathrm{~cm}$ di bawah batas atas horizon argilik atau kandik atau $180 \mathrm{~cm}$ di bawah permukaan tanah mineral (Soil survey staff. 2014). Ultisol memiliki memiliki tingkat kemasaman kurang dari 5,5, bahan organik rendah sampai sedang,dan nutrisi rendah. Ultisol memiliki kandungan $\mathrm{Al}$ yang tinggi dan menyebabkan terfiksasinya unsur fosfat sehingga ketersediaan fosfat di dalam larutan tanah berkisar 0-3 ppm (Munir, 1996).

Pemberian bahan organik dan pemupukan yang optimal merupakan salah satu cara untuk memperbaiki sifat fisik, biologi dan kimia tanah, sehingga meningkatkan ketersediaan unsur hara di dalam tanah menjadi optimal. Salah satu pupuk organik yang dapat diberikan adalah pupuk kompos LCC (Legum cover crop) yang memiliki jumlah serasah yang sangat tinggi yaitu pada tempat ternaung sebanyak 9 ton (setara dengan $263 \mathrm{~kg} \mathrm{~N}, \mathrm{P}, \mathrm{K}, \mathrm{Mg}$ dengan 45$56 \% \mathrm{~N}$ ) dan di daerah terbuka sebanyak 20 ton (setara dengan $531 \mathrm{~kg}$ NPKMg dengan 75$83 \%$ N). Penelitian ini betujuan untuk mengetahui pengaruh pemberian kompos LCC mucuna bracteata pada medium tanah ultisol dan menentukan dosis / takaran pupuk kompos LCC Mucuna Bracteata yang memberikan pertumbuhan bibit kelapa sawit (Elaeis guineensis Jacq) terbaik.

\section{METODE PENELITIAN}

Penelitian ini dilaksanakan di Kebun kelompok tani, Desa Segati, Kab. Pelalawan, Riau. Penelitian dilaksanakan di dalam polybag. Waktu penelitian dilakukanselama 4 bulan dari bulan Februari hingga Mei 2016. Bahan yang digunakan dalam penelitian ini adalah, bibit kelapa sawit umur 4 bulan varietas Tenera yang merupakan varietas hasil persilangan Dura dan Pisifera, Medium ultisol, kompos LCC MB (Mucuna bracteata), polybag $40 \times 35 \mathrm{~cm}$, bioaktifator orgadec, pestisida sevin $85 \mathrm{~S}$ dan fungisida Dithane M45, pupuk RP dan Dolomit serta alat tulis.

Penelitian ini dilaksanakan secara eksperimen dengan Rancangan Acak Lengkap (RAL) yang terdiri atas 5 perlakuan dan 4 ulangan, sehingga seluruhnya 20 unit percobaan. Setiap unit percobaan terdiri dari 2 bibit tanaman dan semuanya digunakan sebagai sampel. Dengan demikian jumlah bibit yang digunakan sebanyak 40 tanaman. Perlakuan pemberian pupuk kompos LCC (P) terdiri dari beberapa taraf yaitu : tanpa pupuk, pupuk kompos LCC Mucuna bracteata 100 g/8kg tanah, pupuk kompos LCC Мисипа bracteata $200 \mathrm{~g} / 8 \mathrm{~kg}$ tanah, pupuk kompos LCC Mucuna bracteata $300 \mathrm{~g} / 8 \mathrm{~kg}$ tanah dan pupuk kompos LCC Mucuna bracteata 400 $\mathrm{g} / 8 \mathrm{~kg}$ tanah. Data yang diperoleh dianalisis secara statistik dengan analisis ragam atau analysis of variance (ANOVA). Hasil analisis ragam yang menunjukkan adanya perbedaan nyata, diteruskan dengan Uji Lanjut Beda Nyata Jujur (BNJ) pada taraf 5\%. Parameter yang diamati adalah sifat tanah yang digunakan untuk penelitian, serapan hara N P $\mathrm{K}$, pertambahan tinggi bibit, pertambahan jumlah daun, pertambahan lilit batang, pertambahan volume akar, berat kering dan kandungan kompos LCC Mucuna bracteata.

\section{HASIL DAN PEMBAHASAN}

\section{Sifat Tanah yang Digunakan untuk Penelitian}

Hasil analisis tekstur dan sifat kimia tanah yang digunakan sebagai media pertumbuhan tanaman pada penelitian dapat dilihat pada tabel 1 .

Dari hasil penelitian yang telah dilakukan bahwa peningkatan dosis pupuk kompos LCC Mucuna bracteata dapat memperbaiki sebagian besar sifat kimia tanah seperti $\mathrm{PH}\left(\mathrm{H}_{2} \mathrm{O}\right), \mathrm{PH}(\mathrm{KCL}), \mathrm{C}$ organik pada, 
$\mathrm{N}$ total, $\mathrm{C} / \mathrm{N}$, dan KTK sehingga pertumbuhan bibit menjadi lebih baik. Pada analisis kandungan K-dd terjadi peningkatan, sedangkan untuk Mg-dd dan Ca-dd tidak ada kenaikan dan pada kandungan $\mathrm{P}_{2} \mathrm{O}_{5}$ tidak ada kenaikan nilai dari tanah awal hingga pengamatan akhir.

Tabel 1. Tekstur dan Sifat Kimia Tanah Ultisol Sebelum dan Sesudah Penelitian.

\begin{tabular}{|c|c|c|c|c|c|}
\hline \multirow{2}{*}{ Sifat kimia tanah } & \multirow{2}{*}{ Satuan } & \multicolumn{4}{|c|}{ Pengamatan } \\
\hline & & Awal & Kriteria & Akhir * & Kriteria \\
\hline $\mathrm{PH}\left(\mathrm{H}_{2} \mathrm{O}\right)$ & & 4,36 & Sangat masam & 5,96 & Masam \\
\hline PH (KCL) & & 4,09 & Sangat masam & 5,12 & Masam \\
\hline C Organik & $\%$ & 1,41 & Rendah & 5,58 & Sangat tinggi \\
\hline N Total & $\%$ & 0,10 & Sangat rendah & 0,19 & Rendah \\
\hline $\mathrm{C} / \mathrm{N}$ & & 14,1 & Sedang & 29,3 & Sangat tinggi \\
\hline $\mathrm{P}_{2} \mathrm{O}_{5}$ & Ppm & 2,46 & Sangat rendah & 2,57 & Sangat rendah \\
\hline K-dd & $\mathrm{Cmol} / \mathrm{kg}$ & 0,19 & Rendah & 0,23 & Sedang \\
\hline Mg-dd & $\mathrm{Cmol} / \mathrm{kg}$ & 0,15 & Sangat rendah & 0,21 & Sangat rendah \\
\hline Ca-dd & $\mathrm{Cmol} / \mathrm{kg}$ & 0,37 & Sangat rendah & 0,39 & Sangat rendah \\
\hline KTK & $\mathrm{Cmol} / \mathrm{kg}$ & 4,32 & Sangat rendah & 7,12 & Rendah \\
\hline Pasir & $\%$ & 48,4 & \multirow{3}{*}{$\begin{array}{l}\text { Lempung liat } \\
\text { berpasir }\end{array}$} & 44,4 & \multirow{3}{*}{$\begin{array}{l}\text { Lempung liat } \\
\text { berpasir }\end{array}$} \\
\hline Liat & $\%$ & 34,0 & & 38,0 & \\
\hline Debu & $\%$ & 17,6 & & 17,6 & \\
\hline
\end{tabular}

Keterangan * : Sample tanah penelitian dengan dosis $400 \mathrm{~g} / 8 \mathrm{~kg}$ tanah

Peningkatan $\mathrm{pH}$ tanah akibat peningkatan dosis pupuk LCC Mucuna bracteata disebabkan oleh asam-asam organik berupa asam humat dan asam fulvat yang dihasilkan selama proses dekomposisi, asamasam organik mempunyai muatan negatif yang mampu mengikat kation-kation. Bahan organik Mucuna bracteata mampu meningkatkan $\mathrm{pH}$ tanah karena bahan organik yang terdekomposisi dan termineralisasi melepaskan unsur-unsur hara termasuk basa-basa.

Diduga aktifitas basa-basa tersebut mampu meningkatkan nilai $\mathrm{pH}$ tanah akibat berkurangnya pengaruh asam-asam organik. Hal ini sesuai dengan pernyataan Saif (1985) bahwa reaksi tanah yang bersifat masam yang disebabkan oleh ion $\mathrm{H}^{+}$pada larutan tanah dapat dikurangi dengan menggunakan senyawa yang bersifat basa. Wahyudi (2009) menambahkan bahwa asam humat dan asam fulvat dari hasil dekomposisi bahan organik berperan penting dalam mereduksi $\mathrm{Al}$ pada tanah sehingga produksi ion $\mathrm{H}^{+}$akibat terhidrolisisnya $\mathrm{Al}$ akan menurun. Gugus karboksil (-COOH) dan gugus hidroksil $\left(\mathrm{OH}^{-}\right)$ yang terdapat pada asam-asam organik akan meningkatkan aktivitas ion $\mathrm{OH}^{-}$. Ion ini akan menetralisir konsentrasi ion $\mathrm{H}^{+}$yang berada dalam larutan tanah, sehingga dapat meningkatkan $\mathrm{pH}$ tanah.

Peningkatan C-organik tanah akibat peningkatan dosis pupuk LCC Mucuna bracteata disebabkan oleh bahan organik
Mucuna bracteata yang mengalami dekomposisi. Hal ini sesuai dengan hasil penelitian Syukur dan Indah (2006), bahwa aplikasi kompos dan pupuk kandang dapat meningkatkan kandungan C-organik tanah. Semakin banyak pupuk organik yang ditambahkan ke dalam tanah, semakin besar peningkatan kandungan C-organik dalam tanah.

Menurut Hakim et al, (1986), KTK tanah sangat dipengaruhi oleh fraksi liat dan kandungan bahan organik tanah. Bahan organik memiliki gugus fungsional yang dapat menyumbangkan muatan negatif dari bahan pada tanah. Muatan negatif dari bahan organik tersebut mampu mempertukarkan kation dalam tanah sehingga mampu meningkatkan kapasitas tukar kation tanah. Peningkatan dosis pupuk LCC Mucuna bracteata akan menghasilkan peningkatan bahan organik dari proses dekomposisi Mucuna bracteata. Semakin tinggi penambahan dosis pupuk LCC Mucuna bracteata maka semakin tinggi bahan organik yang ditambahkan dalam tanah. Menurut Hardjowigeno (2010), juga menjelaskan bahwa tanah - tanah dengan kandungan bahan organik tinggi mempunyai KTK lebih tinggi daripada tanah-tanah dengan kandungan bahan organik rendah.

Rendahnya kation $\mathrm{K}^{+}, \mathrm{Ca}^{2+}, \mathrm{Mg}^{2+}$ seperti yang ditunjukkan hasil analisis di atas (tabel 1), disebabkan karena kation-kation ini mudah tercuci oleh air perkolasi dan 
dilepaskan kedalam horizon tanah. Menurut Adiwiganda et al, (1995) rendahnya kandungan kation-kation dapat ditukar tersebut di dalam tanah $\left(\mathrm{K}^{+}, \mathrm{Ca}^{2+}, \mathrm{Mg}^{2+}\right.$ dan $\left.\mathrm{Na}^{+}\right)$ karena tanah didominasi oleh koloid liat beraktivitas rendah. Musa et al, (2006), menjelaskan bahwa KTK merupakan kemampuan tanah dalam mengikat dan mempertukarkan kation, jika KTK tanah rendah, maka kemampuan tanah dalam mengikat kation menjadi rendah.

\section{Efisiensi Pemakaian Hara}

\section{Serapan Hara N, P, K}

Dobermann (2007) menyatakan bahwa

efisiensi serapan dipengaruhi oleh

Tabel 2. Serapan Hara N, P, K Bibit Kelapa Sawit Umur 8 Bulan dengan Pemberian Pupuk Kompos LCC Mucuna Bracteata pada Medium Ultisol.

\begin{tabular}{cccc}
\hline Pupuk kompos LCC Mucuna bracteata & \multicolumn{3}{c}{ Serapan Hara $(\mathrm{g})$} \\
\cline { 2 - 4 }$(\mathrm{g} / 8 \mathrm{~kg}$ tanah) & $\mathrm{N}$ & $\mathrm{P}$ & $\mathrm{K}$ \\
\hline Tanpa pupuk & $0,52 \mathrm{c}$ & $0,035 \mathrm{c}$ & $0,16 \mathrm{c}$ \\
100 & $1,16 \mathrm{a}$ & $0,071 \mathrm{a}$ & $0,34 \mathrm{ab}$ \\
200 & $0,74 \mathrm{bc}$ & $0,047 \mathrm{bc}$ & $0,32 \mathrm{ab}$ \\
300 & $0,84 \mathrm{~b}$ & $0,052 \mathrm{~b}$ & $0,39 \mathrm{a}$ \\
400 & $0,65 \mathrm{bc}$ & $0,040 \mathrm{bc}$ & $0,28 \mathrm{~b}$ \\
\hline
\end{tabular}

\section{Efisiensi Serapan Hara, Efisiensi Fisiologi dan Efisiensi Agronomis} serapan hara N,P,K tertinggi diperoleh dari perlakuan dosis $100 \mathrm{~g} / 8 \mathrm{~kg}$ tanah yaitu sebesar $17,08 \%$. Hal ini mengindikasikan bahwa sekitar $82,92 \%$ hara $\mathrm{N}$ hilang dari sejumlah hara $\mathrm{N}$ yang diberikan. Sedangkan untuk efisiensi serapan hara $\mathrm{N}$ terendah diperoleh pada perlakuan dosis $200-400 \mathrm{~g} / 8 \mathrm{~kg}$ tanah yaitu sebesar $0,83 \%$ - 2,98\% atau hal ini mengindikasikan bahwa sekitar 97,02\% $99,17 \%$ hara $\mathrm{N}$ hilang dari sejumlah hara $\mathrm{N}$ yang diberikan. Nilai efisiensi serapan hara $\mathrm{N}$ dengan hasil penelitian terdahulu yang menyatakan bahwa nilai serapan hara $\mathrm{N}$ oleh tanaman umumnya sebesar 30-50 \% (Sheoran et al., 2016). Hal ini disebabkan sangat dinamisnya hara $\mathrm{N}$ di dalam tanah, dimana hara $\mathrm{N}$ mengalami denitrifikasi dan terkadang termobilisasi didalam bahan organik tanah.

Diketahui bahwa efisiensi serapan hara $\mathrm{P}$ tertinggi diperoleh pada perlakuan dosis $100 \mathrm{~g} / 8 \mathrm{~kg}$ tanah yaitu sekitar $9,64 \%$ atau hal ini mengindikasikan bahwa sekitar $90,36 \%$ hara $\mathrm{P}$ hilang dari sejumlah hara $\mathrm{P}$ yang diberikan. Sedangkan efisiensi serapan hara terendah diperoleh pada perlakuan dosis 200 dan 400
Pada Tabel 3 diketahui bahwa efisiensi tersebut masih terlalu kecil jika dibandingkan keseimbangan antara kebutuhan tanaman dengan jumlah hara yang dilepas dari pupuk. Selanjutnya Tambunan et al, (2014) juga menyatakan bahwa hal yang mempengaruhi efisiensi hara adalah unsur hara yang dilepas oleh pupuk, semakin banyak hara yang dilepas oleh pupuk maka akan semakin tinggi efisiensi pemupukan.

Selain itu, serapan hara juga berhubungan erat dengan perkembangan perakaran tanaman. Pada perkembangan akar yang baik maka serapan hara juga akan semakin baik. $\mathrm{g} / 8 \mathrm{~kg}$ tanah yaitu $0,36 \%$ atau hal ini menunjukkan bahwa 99,64\% hara P hilang dari sejumlah hara $\mathrm{P}$ yang telah diberikan. Efisiensi hara $\mathrm{P}$ umumnya rendah, hal ini dikarenakan hara $\mathrm{P}$ merupakan salah satu hara yang memiliki mobilitas dan ketersediaan yang rendah di dalam tanah yang disebabkan oleh adanya fiksasi P oleh unsur lain (Robert, 2008; Shaheen et al., 2007).

Efisiensi serapan hara $\mathrm{K}$ tertinggi diperoleh pada perlakuan dosis $100 \mathrm{~g} / 8 \mathrm{~kg}$ tanah yaitu $5,95 \%$ atau hal ini menunjukkan bahwa $94,05 \%$ hara $\mathrm{P}$ hilang dari sejumlah hara $\mathrm{P}$ yang diberikan. Sedangkan efisiensi serapan hara $P$ terendah diperoleh pada perlakuan dosis $200-400 \mathrm{~g} / 8 \mathrm{~kg}$ tanah yaitu $2,59 \%$ - $1,00 \%$ atau sama halnya dengan hilangnya sejumlah hara $\mathrm{P}$ yang diberikan sebesar $97,41 \%-99,00 \%$.

Pada Tabel 3 menunjukkan bahwa efisiensi fisiologi dari masing - masing perlakuan bervariasi terhadap masing - masing jenis hara. Efisiensi fisiologi hara $\mathrm{P}$ tertinggi pada perlakuan dosis $400 \mathrm{~g} / 8 \mathrm{~kg}$ tanah yakni $11.487,99 \mathrm{~g}$, hal ini berbeda dengan perlakuan dosis 100 - $300 \mathrm{~g} / 8 \mathrm{~kg}$ tanah. Selanjutnya efisiensi fisiologi hara $\mathrm{K}$ tertinggi diperloleh dari perlakuan dosis $400 \mathrm{~g} / 8 \mathrm{~kg}$ tanah yaitu sebesar 542,32 g. Sedangkan efisiensi fisiologi 
hara $\mathrm{K}$ terendah diperoleh dari perlakuan dosis $100 \mathrm{~g} / 8 \mathrm{~kg}$ tanah yaitu sebesar 86,47 g. Sementara itu efisiensi fisiologi hara $\mathrm{N}$ tertinggi diperoleh dari perlakuan dosis 400 g/8kg tanah yaitu sebesar 494,01 g. Sedangkan efisiensi fisiologi hara $\mathrm{N}$ terendah diperoleh dari perlakuan dosis $100 \mathrm{~g} / 8 \mathrm{~kg}$ tanah yaitu $36,78 \mathrm{~g}$.

Tabel 3. Efisiensi Serapan Hara, Efisiensi Fisiologi dan Efisiensi Agronomi Bibit Kelapa Sawit Umur 8 Bulan dengan Pemberian Pupuk Kompos LCC Mucuna Bracteata pada Medium Ultisol.

\begin{tabular}{|c|c|c|c|}
\hline \multirow{2}{*}{$\begin{array}{l}\text { Pupuk kompos LCC Mucuna bracteata } \\
\text { (g/8 kg tanah) }\end{array}$} & \multicolumn{3}{|c|}{ Serapan Hara (g) } \\
\hline & $\mathrm{N}$ & $\mathrm{P}$ & $\mathrm{K}$ \\
\hline 100 & $17,08 \mathrm{a}$ & $9,64 \mathrm{a}$ & $5,95 \mathrm{a}$ \\
\hline 200 & $2,98 \mathrm{~b}$ & $1,67 \mathrm{~b}$ & $2,59 \mathrm{~b}$ \\
\hline 300 & $2,82 b$ & $1,50 \mathrm{~b}$ & $2,57 \mathrm{~b}$ \\
\hline 400 & $17,08 \mathrm{a}$ & $0,36 \mathrm{~b}$ & $1,00 \mathrm{~b}$ \\
\hline \multirow{2}{*}{$\begin{array}{l}\text { Pupuk kompos LCC Mucuna bracteata } \\
\text { (g/8 kg tanah) }\end{array}$} & \multicolumn{3}{|c|}{ Efisiensi Fisiologi (g) } \\
\hline & $\mathrm{N}$ & $\mathrm{P}$ & $\mathrm{K}$ \\
\hline 100 & $36,78 \mathrm{c}$ & $635,24 \mathrm{~b}$ & $86,47 \mathrm{~d}$ \\
\hline 200 & $158,23 \mathrm{~b}$ & $2.854,20 \mathrm{~b}$ & $216,68 \mathrm{c}$ \\
\hline 300 & $202,90 \mathrm{~b}$ & $3.671,10 \mathrm{~b}$ & $286,64 \mathrm{~b}$ \\
\hline 400 & $494.01 \mathrm{a}$ & $11.487,99 \mathrm{a}$ & $542,32 \mathrm{a}$ \\
\hline \multirow{2}{*}{$\begin{array}{l}\text { Pupuk kompos LCC Mucuna bracteata } \\
\text { (g/8 kg tanah) }\end{array}$} & \multicolumn{3}{|c|}{ Efisiensi Agronomi (g) } \\
\hline & $\mathrm{N}$ & $\mathrm{P}$ & $\mathrm{K}$ \\
\hline 100 & $6,32 \mathrm{a}$ & $61,42 \mathrm{a}$ & $8,04 \mathrm{a}$ \\
\hline 200 & $4,22 \mathrm{a}$ & $40,96 \mathrm{a}$ & $5,36 \mathrm{a}$ \\
\hline 300 & $5,73 \mathrm{a}$ & $55,61 \mathrm{a}$ & $7,28 \mathrm{a}$ \\
\hline 400 & $4,08 \mathrm{a}$ & $39,66 \mathrm{a}$ & $5,19 \mathrm{a}$ \\
\hline
\end{tabular}

Pola efisiensi fisiologi dari yang terbesar sampai dengan yang terkecil adalah $\mathrm{P}>\mathrm{K}>\mathrm{N}$. Pola ini menggambarkan bahwa dalam penelitian ini, hara $\mathrm{P}$ merupakan hara yang memiliki kontribusi yang paling besar terhadap peningkatan berat kering tanaman, diikuti hara $\mathrm{K}$ dan hara N. Dengan kata lain, dibanding hara $\mathrm{K}$ dan $\mathrm{N}$ tanaman memberikan respon yang paling besar terhadap hara P. Hal ini mungkin disebabkan hara $\mathrm{P}$ merupakan hara yang menjadi faktor pembatas terbesar terhadap pertumbuhan dan perkembangan tanaman dibanding hara lainnya.

Pada Tabel 3 menunjukkan bahwa efisiensi agronomi tertinggi terdapat pada hara $\mathrm{P}$ kemudian hara $\mathrm{K}$ dan yang paling kecil terdapat pada hara N. Pola nilai efisiensi agronomi ini berbanding terbalik dengan pola banyaknya hara yang diberikan, dimana dalam penelitian ini jumlah hara yang diberikan dari yang terbesar sampai dengan terkecil mengikuti pola N, K, P. Hasil ini membuktikan bahwa jika hara $\mathrm{N}, \mathrm{P}$, dan $\mathrm{K}$ diberikan secara bersamaan, maka nilai efisiensi agronomi masing - masing hara berbanding terbalik terhadap jumlah masing - masing hara yang diberikan. Dengan kata lain berarti semakin kecil jumlah suatu hara yang diberikan dibandingkan hara lainnya maka akan semakin tinggi nilai efisiensi hara tersebut dibandingkan hara lainnya.

\section{Variabel Pertumbuhan Tanaman 1. Pertambahan Tinggi Bibit}

Pemberian dosis pupuk kompos LCC Mucuna Bracteata $400 \mathrm{~g} / 8 \mathrm{~kg}$ tanah dapat meningkatkan pertambahan tinggi bibit kelapa sawit sebanyak $45,71 \%$ atau $26,11 \mathrm{~cm}$ dibandingkan dengan perlakuan tanpa pupuk. Hubungan peningkatan dosis pupuk kompos LCC Mucuna bracteata dengan pertambahan tinggi tanaman dapat dilihat pada tabel 4 .

\section{Pertambahan Jumlah Daun (Helai)}

Tabel 5 menunjukkan bahwa pemberian pupuk kompos LCC Mucuna Bracteata menghasilkan perbedaan yang nyata antar parameter. Peningkatan dosis pupuk kompos LCC Mucuna Bracteata $400 \mathrm{~g} / 8 \mathrm{~kg}$ tanah nyata lebih tinggi meningkatkan pertambahan jumlah daun bibit kelapa sawit sebanyak 38,51\% atau 3,37 helai dibandingkan dengan dosis tanpa pupuk. Namun pada perlakuan kompos $L C C$ Mucuna Bracteata dengan dosis $200 \mathrm{~g} / 8 \mathrm{~kg}$ tanah tidak berbeda nyata terhadap perlakuan pemberian kompos LCC Mucuna Bracteata dengan dosis $100 \mathrm{~g} / 8 \mathrm{~kg}$ tanah. Hubungan peningkatan dosis pupuk kompos LCC Mucuna bracteata dengan pertambahan jumlah 
daun dapat dilihat pada grafik regresi dibawah

ini.

Tabel 4. Pertambahan Tinggi Bibit Kelapa Sawit Umur 8 Bulan dengan Pemberian Pupuk Kompos LCC Mucuna Bracteata pada Medium Ultisol.

\begin{tabular}{cccc}
\hline $\begin{array}{c}\text { Pupuk kompos LCC Mucuna Bracteata } \\
\text { (g/8 kg tanah) }\end{array}$ & Tinggi Awal $(\mathrm{cm})$ & Tinggi Akhir $(\mathrm{cm})$ & $\begin{array}{c}\text { Pertambahan Tinggi } \\
\text { Bibit }(\mathrm{cm})\end{array}$ \\
\hline Tanpa pupuk & 23.30 & 54.30 & $31.00 \mathrm{a}$ \\
100 & 24.00 & 65.61 & $41.61 \mathrm{a}$ \\
200 & 25.21 & 72.97 & $47.76 \mathrm{a}$ \\
300 & 24.81 & 78.66 & $53.85 \mathrm{a}$ \\
400 & 25.57 & 82.68 & $57.11 \mathrm{a}$ \\
\hline
\end{tabular}

Angka- angka yang diikuti oleh huruf kecil yang tidak sama pada kolom yang sama, berbeda nyata menurut BNJ pada taraf $5 \%$

Tabel 5. Pertambahan Jumlah Daun Bibit Kelapa Sawit Umur 8 Bulan dengan Pemberian Pupuk Kompos LCC Mucuna Bracteata pada Medium Ultisol.

\begin{tabular}{cccc}
\hline $\begin{array}{c}\text { Pupuk kompos LCC Mucuna Bracteata } \\
\text { (g/8 kg tanah) }\end{array}$ & $\begin{array}{c}\text { Jumlah Awal } \\
\text { (helai) }\end{array}$ & $\begin{array}{c}\text { Jumlah Akhir } \\
\text { (helai) }\end{array}$ & $\begin{array}{c}\text { Pertambahan Jumlah } \\
\text { Daun (helai) }\end{array}$ \\
\hline Tanpa pupuk & 4 & 9.37 & $5.38 \mathrm{~d}$ \\
100 & 4 & 10.50 & $6.50 \mathrm{c}$ \\
200 & 4 & 11.37 & $7.38 \mathrm{bc}$ \\
300 & 4 & 11.50 & $7.50 \mathrm{~b}$ \\
400 & 4 & 12.75 & $8.75 \mathrm{a}$ \\
\hline
\end{tabular}

Angka- angka yang diikuti oleh huruf kecil yang tidak sama pada kolom yang sama, berbeda nyata menurut BNJ pada taraf $5 \%$.

\section{Pertambahan Lilit Batang}

Tabel 6 menunjukkan bahwa peningkatan dosis pupuk kompos LCC Mucuna Bracteata dari $0 \mathrm{~g}$ hinggah $300 \mathrm{~g} / 8 \mathrm{~kg}$ tanah nyata meningkatkan pertambahan lilit batang bibit kelapa sawit. Peningkatan dosis pupuk kompos LCC Mucuna Bracteata 300 $\mathrm{g} / 8 \mathrm{~kg}$ tanah meningkatkan pertambahan lilit batang sebesar $51,28 \%$ atau $5,8 \quad \mathrm{~cm}$

Tabel 6. Pertambahan Lilit Batang Bibit Kelapa Sawit Umur 8 Bulan dengan Pemberian Pupuk Kompos LCC Mucuna Bracteata pada Medium Ultisol.

\begin{tabular}{cccc}
\hline $\begin{array}{c}\text { Pupuk kompos LCC Mucuna Bracteata } \\
\text { (g/8 kg tanah) }\end{array}$ & $\begin{array}{c}\text { Jumlah Awal } \\
(\mathrm{cm})\end{array}$ & $\begin{array}{c}\text { Jumlah Akhir } \\
(\mathrm{cm})\end{array}$ & $\begin{array}{c}\text { Pertambahan lilit } \\
\text { batang }(\mathrm{cm})\end{array}$ \\
\hline Tanpa pupuk & 3.57 & 9.08 & 9.08 \\
100 & 3.88 & 11.06 & 11.06 \\
200 & 3.91 & 13.08 & 13.08 \\
300 & 4.07 & 15.38 & 15.38 \\
400 & 3.90 & 15.25 & 15.25 \\
\hline
\end{tabular}

Angka- angka yang diikuti oleh huruf kecil yang tidak sama pada kolom yang sama, berbeda nyata menurut BNJ pada taraf $5 \%$.

\section{Volume Akar}

Tabel 7 menunjukkan bahwa peningkatan dosis pupuk kompos LCC Mucuna Bracteata dari $0 \mathrm{~g}$ hinggah $400 \mathrm{~g} / 8 \mathrm{~kg}$ tanah nyata meningkatkan pertambahan volume akar bibit kelapa sawit. Peningkatan dosis pupuk kompos LCC Mucuna Bracteata dibandingkan dengan tanpa pupuk, namun peningkatan dosis $400 \mathrm{~g} / 8 \mathrm{~kg}$ tanah tidak berbeda nyata dengan dosis $300 \mathrm{~g} / 8 \mathrm{~kg}$ tanah. Hubungan peningkatan dosis pupuk kompos LCC Mucuna bracteata dengan pertambahan lilit batang dapat dilihat pada grafik regresi dibawah ini.
$400 \mathrm{~g} / 8 \mathrm{~kg}$ tanah meningkatkan pertambahan volume akar sebesar $67,92 \%$ atau $90,0 \mathrm{ml}$ dibandingkan dengan tanpa pupuk. Hubungan peningkatan dosis pupuk kompos LCC Mucuna bracteata dengan pertambahan volume akar dapat dilihat pada grafik regresi dibawah ini. 
Tabel 7. Pertambahan Volume Akar Bibit Kelapa Sawit Umur 8 Bulan dengan Pemberian Pupuk Kompos LCC Mucuna Bracteata pada Medium Ultisol.

\begin{tabular}{cc}
\hline $\begin{array}{c}\text { Pupuk kompos LCC Mucuna Bracteata } \\
\text { (g/8 kg tanah) }\end{array}$ & Pertambahan lilit batang $(\mathrm{cm})$ \\
\hline Tanpa pupuk & $42.50 \mathrm{~d}$ \\
100 & $62.25 \mathrm{~cd}$ \\
200 & $83.75 \mathrm{bc}$ \\
300 & $97.50 \mathrm{~b}$ \\
400 & 132.50 \\
\hline
\end{tabular}

$\overline{\text { Angka- angka yang diikuti oleh huruf kecil yang tidak sama pada kolom yang sama, berbeda nyata menurut BNJ pada taraf }}$ $5 \%$.

\section{Berat Kering Bibit}

Tabel 8 menunjukkan bahwa peningkatan dosis pupuk kompos LCC Mucuna Bracteata nyata meningkatkan pertambahan berat kering bibit kelapa sawit. Pemberian 100 - $200 \mathrm{~g} / 8 \mathrm{~kg}$ tanah tidak meningkatkan pertambahan berat kering bibit. Pemberian kompos LCC Mucuna Bracteata dengan dosis $300 \mathrm{~g} / 8 \mathrm{~kg}$ tanah nyata lebih tinggi meningkatkan berat kering bibit kelapa sawit sebanyak 76,04 g atau $71 \%$ dibandingkan dengan tanpa pemberian pupuk. Hubungan peningkatan dosis pupuk kompos LCC Mucuna bracteata dengan berat kering tanaman dapat dilihat pada grafik regresi dibawah ini.

Tabel 8. Pertambahan Berat Kering Bibit Kelapa Sawit Umur 8 Bulan dengan Pemberian Pupuk Kompos LCC Mucuna Bracteata pada Medium Ultisol.

\begin{tabular}{cccc}
\hline $\begin{array}{c}\text { Pupuk kompos LCC Mucuna Bracteata } \\
\text { (g/8 kg tanah) }\end{array}$ & $\begin{array}{c}\text { Berat Kering } \\
\text { Tajuk }(\mathrm{g})\end{array}$ & $\begin{array}{c}\text { Berat Kering } \\
\text { Akar }(\mathrm{g})\end{array}$ & Berat Kering $(\mathrm{g})$ \\
\hline Tanpa pupuk & 22.25 & 9.06 & $31.31 \mathrm{c}$ \\
100 & 45.71 & 14.21 & $59.93 \mathrm{~b}$ \\
200 & 53.54 & 18.64 & $72.18 \mathrm{~b}$ \\
300 & 85.98 & 21.37 & $107.35 \mathrm{a}$ \\
400 & 82.84 & 24.46 & $107.30 \mathrm{a}$ \\
\hline
\end{tabular}

Angka- angka yang diikuti oleh huruf kecil yang tidak sama pada kolom yang sama, berbeda nyata menurut BNJ pada taraf $5 \%$.

\section{Rasio Tajuk Akar}

Tabel 9 menunjukkan bahwa rasio tajuk akar bibit kelapa sawit tidak berbeda nyata akibat perlakuan berbagai dosis pupuk kompos LCC Mucuna bracteata. Rasio tajuk akar bibit kelapa sawit tertinggi ditunjukkan oleh

Tabel 9. Pertambahan Rasio Tajuk Akar Bibit Kelapa Sawit Umur 8 Bulan dengan Pemberian Pupuk Kompos LCC Mucuna Bracteata pada Medium Ultisol.

\begin{tabular}{cccc}
\hline $\begin{array}{c}\text { Pupuk kompos LCC Mucuna Bracteata } \\
\text { (g/8 kg tanah) }\end{array}$ & $\begin{array}{c}\text { Berat Kering } \\
\text { Tajuk }(\mathrm{g})\end{array}$ & $\begin{array}{c}\text { Berat Kering } \\
\text { Akar }(\mathrm{g})\end{array}$ & Rasio Tajuk Akar (g) \\
\hline Tanpa pupuk & 22,25 & 9,06 & 2,46 \\
100 & 45,71 & 14,22 & 3,22 \\
200 & 53,54 & 18,64 & 2,87 \\
300 & 85,98 & 21,37 & 4,02 \\
400 & 82,84 & 24,46 & 3,38 \\
\hline
\end{tabular}

Angka- angka yang diikuti oleh huruf kecil yang tidak sama pada kolom yang sama, berbeda nyata menurut BNJ pada taraf $5 \%$.

Peran akar dalam pertumbuhan tanaman sama pentingnya dengan tajuk, tajuk berfungsi untuk menyediakan karbohidrat melalui proses fotosintesis, maka fungsi akar adalah menyediakan unsur hara dan air yang diperlukan dalam metabolisme tanaman. Hasil perlakuan dosis $300 \mathrm{~g} / 8 \mathrm{~kg}$ tanah yaitu sebesar 4,02 g. Sedangkan rasio tajuk akar bibit kelapa sawit terendah ditunjukkan oleh perlakuan tanpa pupuk yaitu sebesar 2,46 g. dari penyerapan unsur hara seperti nitrogen, fosfor dan kalium menentukan berat kering tanaman. Unsur-unsur tersebut diserap tanaman sebagai nutrisi dan digunakan untuk menyusun jaringan tanaman. Tanaman yang mampu menyerap unsur hara secara optimal 
akan menghasilkan berat kering yang semakin berat pula.

Gardner, dkk.(1991) menyatakan bahwa nilai rasio tajuk akar menunjukan seberapa besar hasil fotosintesis yang terakumulasi pada bagian- bagian tanaman. Hal ini diduga bahwa hasil berat kering melalui proses fotosintesis, lebih banyak ditranslokasikan kebagian tajuk dari pada kebagian akar tanaman. Ratio tajuk akar merupakan faktor penting dalam pertumbuhan tanaman dimana mencerminkan proses penyerapan unsur hara. Untuk bibit tanaman tahunan, ratio tajuk akar yang baik berkisar antara 2,5-3,5.

Terpenuhinya kebutuhan hara dan ketersediaan air bagi tanaman juga sangat menentukan peningkatan rasio tajuk akar. Dwijosapoetro (1985), menyatakan bahwa suatu tanaman akan tumbuh dengan baik bila hara yang dibutuhkan cukup tersedia dalam bentuk yang mudah diserap oleh perakaran tanaman. Semakin membaiknya pertumbuhan tanaman maka akan dapat meningkatkan bobot

Tabel 10. Korelasi antar Variabel Pengamatan. tanaman. Menurut Sarief (1986), dengan pemberian bahan organik ke dalam tanah dapat meningkatkan berat basah dan berat kering dan secara otomatis akan meningkatkan rasio tajuk akar pada tanaman.

\section{Hasil Korelasi Parameter Bibit Kelapa Sawit}

Walpole (1995) menyatakan korelasi merupakan metode statistik yang digunakan untuk mengukur besarnya hubungan linier antara dua variabel atau lebih. Korelasi ini bertujuan untuk melihat/menentukan seberapa erat hubungan antara dua variabel tersebut.

Hasil korelasi menunjukkan bahwa berat kering tanaman berkorelasi sangat kuat dengan lilit batang $(\mathrm{r}=0,950)$, jumlah daun $(\mathrm{r}=0,849)$, Volume akar $(\mathrm{r}=0,878)$, dan berkolerasi lemah dengan komponen tinggi tanaman $(\mathrm{r}=0,549)$, artinya berat kering tanaman yang dihasilkan sangat dipengaruhi oleh lilit batang, jumlah daun dan volume akar tanaman.

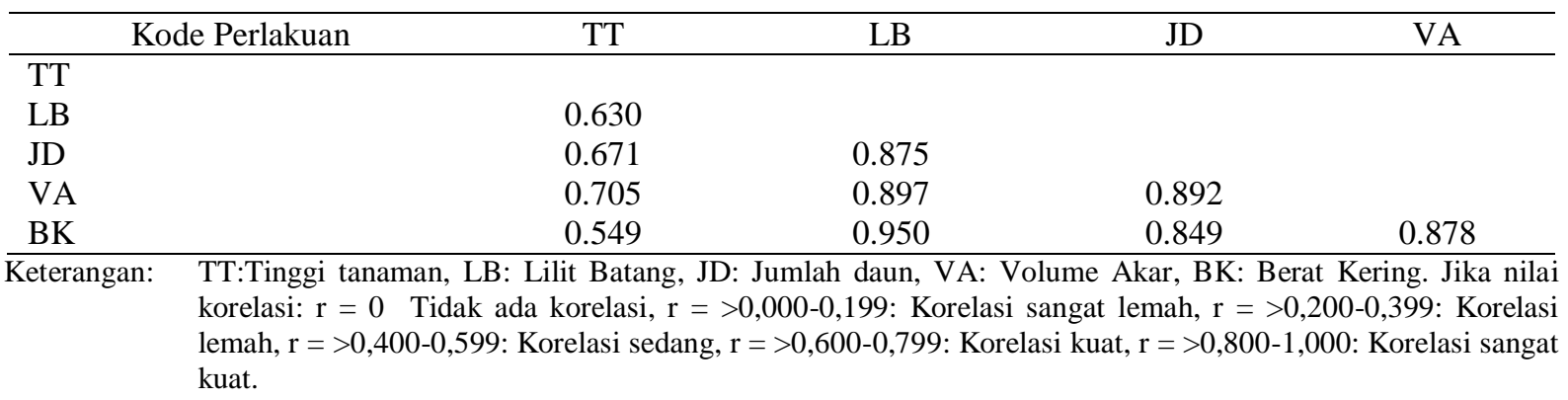

Nurdin (2011) menyatakan pertambahan jumlah daun yang terjadi pada tanaman meningkatkan proses fotosintesis yang menghasilkan senyawa - senyawa organik yang akan ditranslokasikan ke seluruh organ tanaman seperti lilit batang dan volume akar, sehingga berpengaruh terhadap berat kering tanaman. Hal itu berarti bahwa berat kering tanaman ditentukan oleh lilit batang, jumlah daun dan volume akar dan tidak ditentukan oleh tinggi tanaman. Dengan kata lain semakin tinggi lilit batang, jumlah daun, dan volume akar maka semakin tinggi berat kering tanaman.

\section{KESIMPULAN DAN SARAN}

\section{Kesimpulan}

Dari hasil penelitian yang telah dilakukan dapat disimpulkan bahwa,
1. Pemberian pupuk kompos LCC Mucuna Bracteata pada medium Ultisol memberikan pengaruh yang bersifat linier terhadap pertumbuhan bibit kelapa sawit.

2. Pemberian kompos LCC Mucuna bracteata dengan dosis $400 \mathrm{~g} / 8 \mathrm{~kg}$ tanah menghasilkan pertumbuhan terbaik yang ditandai dengan peningkatan pertambahan tinggi bibit, pertambahan jumlah daun, pertambahan lilit batang, pertambahan volume akar dan berat kering bibit kelapa sawit paling tinggi.

\section{Saran}

1. Serapan hara N, P, K dapat ditingkatkan dengan penambahan pupuk kompos LCC Mucuna bracteata.

2. Berdasarkan hasil penelitian yang telah dilakukan untuk mendapatkan pertumbuhan bibit kelapa sawit di pembibitan utama pada media tanah 
Ultisol yang baik disarankan menggunakan kompos LCC Mucuna Bracteata pada dosis $400 \mathrm{~g} / 8 \mathrm{~kg}$ tanah.

\section{DAFTAR PUSTAKA}

Adiwiganda, R., P. Purba, F. Chaniago, Z. Pulungan dan T. Hutomo. 1995. Pedoman Penilaian Kesesuaian Lahan Kelapa Sawit, Pusat Penelitian Kelapa Sawit, Medan.

Anonim. 2008. Mulsa Organik. Online pada: http://www.id.wikipedia.org/wiki/Mulsa . Diakses Tanggal 03 Juni 2014.

Gardner, F.P., R.B. Fearce, dan R.L. Mitchell. 1991. Fisiologi Tanaman Budidaya. UI Press, Jakarta.

Hakim, N., M. Y. Nyakpa, A. M. Lubis, S. G. Nugroho, M.A. Diha, G. B. Hong, dan H. H. Bailley. 1986. Dasar-Dasar Ilmu Tanah. Penerbit Universitas Lampung, Lampung.

Hardjowigeno, S. 1986. Sumber Daya Fisik Wilayah dan Tata Guna Lahan: Histosol. Fakultas Pertanian Institut Pertanian Bogor, Bogor.

Lim, K. H. 2011. Best Management Practices Towards Achieving Vision 35-26 on Peat Soils. Dalam Prosiding Pertemuan Teknis Kelapa Sawit 2011, Batam. 42 59.

Mookma, D. I. and P. Buurman. 1982. Podzols and podzolization in temperate regions. ISM Monograph 1. Int. Soil Museum, Wageningan. P.126.

Musa, L., Mukhlis, dan A. Rauf. 2006. DasarDasar Ilmu Tanah. Universitas Sumatera Utara, Medan.

Nyakpa, M. Y., M. A. Pulung, A. G. Amrah, A. Munawar, G.B. Hong dan N. Hakim. 1988. Kesuburan Tanah. Universitas Lampung, Bandar Lampung.

Saif. 1985. The Effect Amelioran Kinds And Dosages To Oxisol's Zero Charge Pointand Phosphate Retention. Online pada:

http://jurnal.fp.uns.ac.id/index.php/tanah /article/viewFile/111/pdf_11. Diakses Tanggal 11 Mei 2015.

Sevindrajuta. 1996. Peranan Cacing Tanah (Pontoscolex corethrurur) dan Macam Bahan Organik dalam Perbaikan Beberapa Sifat Fisika Ultisol Rimbo Data dan Hasil Kedelai. Tesis (Tidak
Dipublikasikan). Program Pascasarjana, Universitas Andalas, Padang.

Subagjo, H., N. Suharta, dan A. B Siswanto. 2004. Tanah-tanah Pertanian di Indonesia. Dalam Sumberdaya Lahan Indonesia dan Pengelolaannya. Pusat Penelitian Tanah dan Agroklimat. Badan Penelitian dan Pengembangan Pertanian, Departemen Pertanian.

Suriana, N. 1998. Bawang Bawa Untung. Budidaya Bawang Merah \& Bawang Putih. Cahaya Atma Pustaka, Yogyakarta.

Syukur, A. dan N. M. Indah. 2006. Kajian Pengaruh Pemberian Macam Pupuk Organik Terhadap Pertumbuhan dan Hasil Tanaman Jahe di Inceptisol Karanganyar. Jurnal Ilmu Tanah Dan Lingkungan, 6(2): 124-131.

Wahyudi, I. 2009. Manfaat Bahan Organik terhadap Peningkatan Ketersediaan Fosfor dan Penurunan Toksisitas Aluminium di Ultisol. Disertasi Doktor (Tidak Dipublikasikan). Program Pascasarjana, Universitas Brawijaya, Malang. 
